\title{
GRAMÁTICA DE LOS NUEVOS MEDIOS Y MUTACIONES TECNOCULTURALES ESBOZOS PARA UN MAPA DE LA CUESTIÓN
}

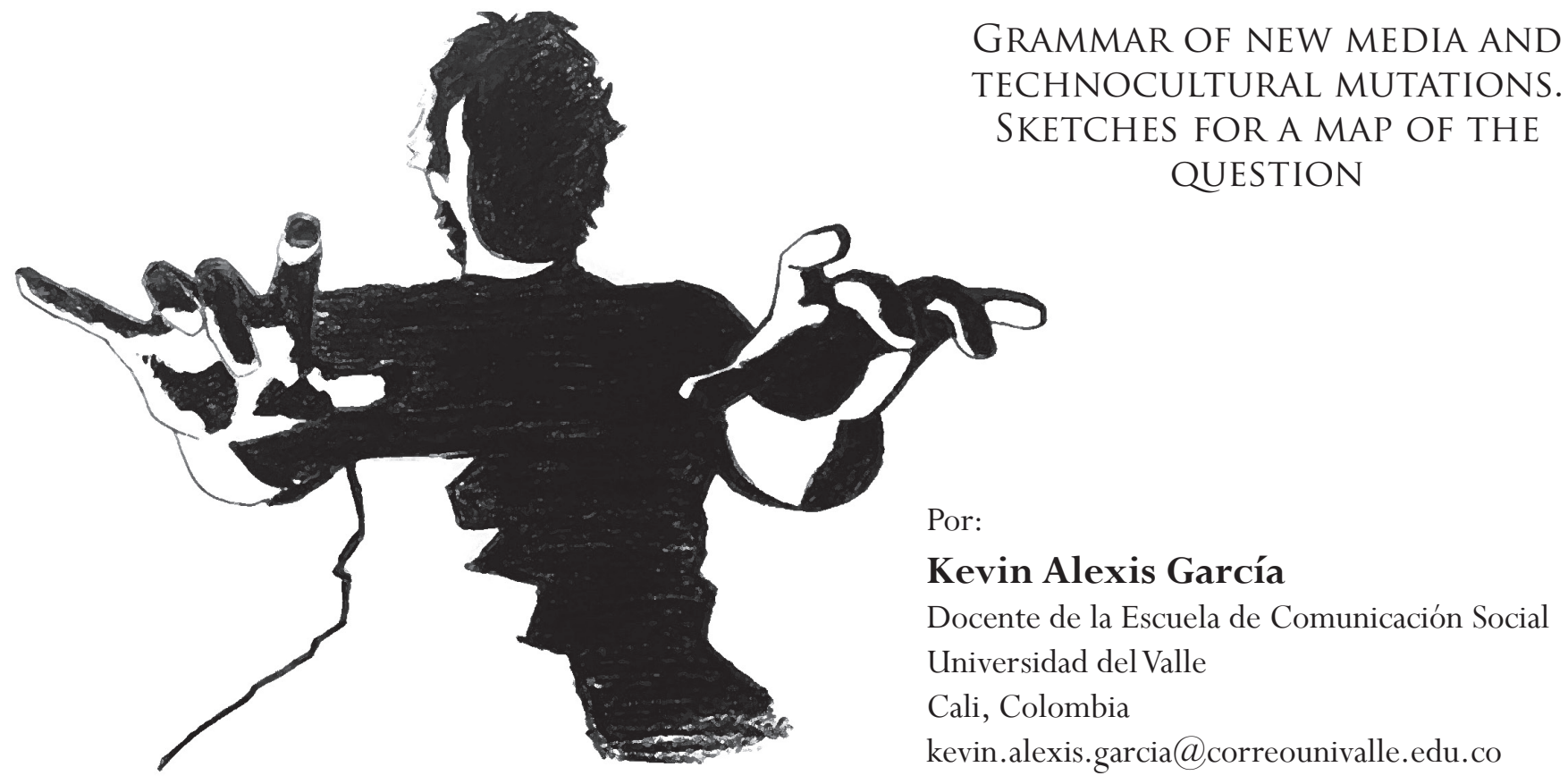

Resumen: Este texto expone una indagación teórica, producto de una fase de exploración investigativa, tendiente a analizar los principios y características de los nuevos medios que han emergido favorecidos por los desarrollos de las tecnologías del ordenador e internet, y las subsecuentes mutaciones tecnoculturales que han propiciado. Como etapa inicial, se esbozan los rasgos de las transformaciones vinculadas al campo periodístico y la escritura, y se sostiene la necesidad de reconocer y analizar el "mensaje" de los nuevos medios, es decir, los cambios que instituyen en las prácticas humanas ${ }^{1}$.

Palabras clave: Nuevos medios, mutación, representación numérica, tecnocultura, hipertexto.

Abstract: This paper presents a theoretical inquiry, result of a phase of exploration research, aimed to analyze the principles and characteristics of new media that have emerged, favored by the development of the technologies of computer and internet, and subsequent technocultural mutations that have propitiated. As an initial step, the features of the transformations are sketched and associated with the field of journalism and writing outlines, and argues the need to recognize and analyze the "message" of new media, it means, instituting changes in human practices.

Keywords: New media, mutation, numerical representation, technoculture, hypertext. 
En 1991 fue anunciada públicamente laWorldWideWeb, una red informática de acceso mundial que se constituía como red de comunicación general; un medio de medios que prometía transformar las interacciones sociales permitiendo el intercambio de datos en múltiples soportes entre usuarios conectados mediante ordenadores alrededor del mundo. Esta tecnología potencializaba las investigaciones y desarrollos que a lo largo de la segunda mitad del siglo XX venían realizando en Estados Unidos laboratorios de empresas tecnológicas, científicos universitarios e investigadores adscritos al Ministerio de Defensa estadounidense. Esta tecnología ya venía siendo utilizada y desarrollada de forma restrictiva entre investigadores de diversas universidades a partir de 1969, fecha en que se transmitió el primer mensaje entre las universidades de Stanford y la UCLA. Se llamó Arpanet la red que precedió a internet y que fue liderada por la Agencia de Investigación de Proyectos Avanzados, perteneciente al Departamento de Defensa de los Estados Unidos. Una década atrás, en 1958, la compañía Bell había creado el primer módem que permitía transmitir datos binarios sobre una línea telefónica. No obstante, este sistema soportado principalmente sobre ordenadores se cimienta sobre estudios que se remontan a 1936, año en el cual el matemático británico Alan Turing escribió un artículo titulado "Sobre los números computables" en el cual teorizaba la posibilidad de crear un ordenador de uso general que más tarde sería llamado la "máquina universal de Turing”.

Lo que años después se conocería como el ordenador es una invención tecnológica que atiende dos características significativas de su época: la hegemonía de los medios de masas y la creciente necesidad de los Estados de administrar registros complejos de datos; ambos elementos (los medios y los datos) operarán como tecnologías complementarias en los ordenadores (Manovich, 2005, p.69).

Como desarrollo auspiciado por el gobierno norteamericano, la red constituía una defensa estratégica para el intercambio y preservación de información. Su estructura es descentrada, desjerarquizada e hiperconectada; sus vínculos y redes internas mutan con facilidad. Un sistema con estas características permite proteger intentos de destrucción de información, pues ésta puede alojarse de forma simultánea en múltiples nodos, no indica una central única ni un nivel jerárquico a derribar.

Dos décadas después de su presentación pública esta red informática global ha experimentado un permanente proceso de transformación y crecimiento exponencial. Miles de desarrolladores se han conectado con el entorno del ciberespacio para hacer desarrollos en múltiples áreas y campos del conocimiento humano y la vida social. Internet ha experimentado permanentes actualizaciones y evoluciones a lo largo de sus 23 años de existencia pública; sin embargo, se pueden advertir tres grandes fases: en la primera internet posibilita intercambiar hipertextos en páginas web alojadas de forma estática, agenciadas por administradores web pero sin posibilidades de manipulación e intervención por parte de los usuarios; una segunda etapa deviene como fase de superación de la anterior, conocida como Internet 2.0 y es caracterizada por el desarrollo de lenguajes dinámicos y configuraciones de bases de datos que propiciaron una mayor interacción máquina-usuario; y una tercera etapa que profundiza las características de la etapa anterior (Internet 3.0) y propicia altísimos procesos de personalización en la interacción con los contenidos. 
Internet ha experimentado un crecimiento exponencial y su entorno cibernético hoy se presenta como el ecosistema humano del Tercer Milenio. Sin embargo, los cambios que en su entorno se producen parecieran desbordar nuestra capacidad de adaptarnos a ellos. Su emergencia ha desencadenado un proceso de transformación permanente que tiende a reconfigurar por completo la vida social. Conceptos como brecha digital se han insinuado para llamar la atención sobre formas posibles de rezagos entre las naciones y clases sociales con respecto al acceso y los usos de la tecnología informática. Internet es un sistema dinámico complejo y las variaciones en su estructura generan nuevas trayectorias y transformaciones no siempre predecibles por sus usuarios.

Veamos: Internet ha propiciado la creación de repositorios de archivos distribuidos en múltiples páginas que pueden operar como bibliotecas digitales para consulta y descarga libre. En ellas los contenidos se actualizan mucho más rápido que en las bibliotecas físicas y ofrecen sus contenidos sin restricciones horarias o geográficas. Esto ha generado impactos en los centros culturales y bibliotecas públicas de las ciudades. Hoy los ciudadanos pueden descargar películas y material audiovisual liberado de forma legal, aunque también clandestina, y esto ha causado transformaciones operativas, pero sobre todo, culturales en los videoclubes y tiendas de alquiler. Hoy las aerolíneas anuncian públicamente el itinerario y costo de sus vuelos, los ciudadanos pueden hacer transacciones por internet y planear por si mismos sus viajes sin intermediación de agencias turísticas. Esto ha generado que muchas agencias desaparezcan y las más grandes se vean forzadas a cambiar sus modelos de intermediación para no dejar de existir. Hoy los ciudadanos conectados pueden acceder a millones de páginas informativas en la red y en los últimos años han disminuido los lectores de periódicos físicos. Los medios industriales tradicionales debieron iniciar fuertes procesos de reestructuración para no desaparecer. Cada uno de estos movimientos genera una serie de reacciones en múltiples niveles y escalas sociales que aún no alcanzamos a visualizar en conjunto. Pero estos son solo algunos pocos ejemplos de un fenómeno complejo y multidimensional.

Este proceso de transición aún inestable podría continuar por alrededor de 25 años más hasta un momento de estabilización en que podríamos advertir un nuevo entorno humano. Nos encontramos en la etapa de comprender la complejidad del sistema cibernético, en la etapa temprana de conocer el medio, explorarlo, producir y consumir en él, aventurarnos, procurarnos un mapa de su geografía virtual, fijar hojas de ruta, detectar los caminos inciertos, advertir los trayectos aún insondables, señalar los riesgos, dominar sus herramientas, comprender sus alegorías y metáforas.

Sin embargo, como un hecho natural e inusitado no terminamos de atender con suficiente detalle los cambios que el nuevo medio ha introducido en las prácticas humanas, en las artes de hacer del día a día, en los usos cotidianos, anónimos, en las prácticas del vestir y el comer, en los encuentros familiares, en los hábitos de lectura en espacios públicos e íntimos; en los campos del conocimiento, en el uso del lenguaje, en las subjetividades, en las metáforas con que conocemos y nos comunicamos. 
¿Qué gramáticas de la vida cotidiana local se reconfiguran con los nuevos medios?, ¿Cuál es el significado de estas prácticas de migración y transducción de recursos culturales?, ¿De qué forma se dan estas transiciones?, ¿Qué instancias de la vida íntima y social se desvanecen ante nuestros ojos con aparente naturalidad?, ¿Cómo reprograma las vidas de las personas las tecnologías de los ordenadores e internet?

En 1964 Marshall Mc Luhan, un profesor canadiense de literatura inglesa, publicó Comprender los medios de comunicación, las extensiones del ser humano. Esta obra pronto se convirtió en un referente en Estados Unidos. En ella McLuhan logra una sensible reflexión, clave para esta investigación, sobre los medios de comunicación y las transformaciones que producen en la vida de las personas.

Mc Luhan entiende los medios de comunicación y las tecnologías como extensiones que desarrolla el ser humano de sus sentidos para procurarse un mayor control sobre su entorno. Sabemos que el telégrafo facilitó la escritura a distancia, el teléfono la escucha a distancia y el cine y la televisión la visión a distancia. Sin embargo, su concepción de medio de comunicación y extensión humana es a su vez mucho más extensa. Entiende por medio múltiples tecnologías como la imprenta, la palabra escrita, la vivienda, el vestuario, el dinero, las carreteras, los relojes, la rueda, la bicicleta y el avión.

Durante 20 años Mc Luchan enseñó lo que se conocía como Cultura Pop en universidades de Canadá y Estados Unidos y fue durante ese periodo que pudo comprender los efectos psicológicos de los medios electrónicos y su tendencia a disolver y comprimir las dimensiones del tiempo y el espacio. Mc Luchan pedía entender sus proposiciones como tropos literarios antes que teorías científicas, pero su lectura de los medios ha sido soporte clave para diversos estudios científicos. De ella nos interesa señalar algunas proposiciones. Sostuvo que la electricidad y su capacidad de llegar a muchos lugares de forma instantánea, supuso cambios en la secuencialidad de las prácticas que estimulaba la era mecánica y que "Eléctricamente contraído, el globo no es más que una aldea”. A partir de esa interpretación empezó a postular la existencia de un espíritu mundial e instaló el concepto de Aldea Global. Así como dicho concepto contiene un oxímoron, una aparente contradicción en su significado, Mc Luhan invirtió los significados de la relación entre el medio y su contenido. Señaló que "El medio es el $<<$ mensaje $>>$... las consecuencias individuales y sociales de cualquier medio, es decir, de cualquiera de nuestras extensiones, resultan de la nueva escala que introduce en nuestros asuntos cualquier extensión o tecnología nueva" (Mc Luchan, 1996, p. 29).

Para Mc Luhan cualquier extensión afecta a todo el complejo psíquico y social y ejerce un efecto insospechado en nuestras vidas. Los medios de comunicación son agentes que hacen que algo suceda "Modelamos nuestras herramientas y luego éstas nos modelan a nosotros”. Por el contrario son los contenidos del medio los que nos impiden ver su carácter. El mensaje de cualquier medio o tecnología es el cambio de escala, ritmo o patrones que introduce en las prácticas humanas. Es el medio el que modela las formas de asociaciones y trabajo de las personas. Distraídos por los contenidos "Los efectos de la tecnología no se producen al nivel de las opiniones o de los conceptos, sino que modifican los índices sensoriales, o pautas de percepción, regularmente y sin encontrar resistencia" (1996, p. 39). 


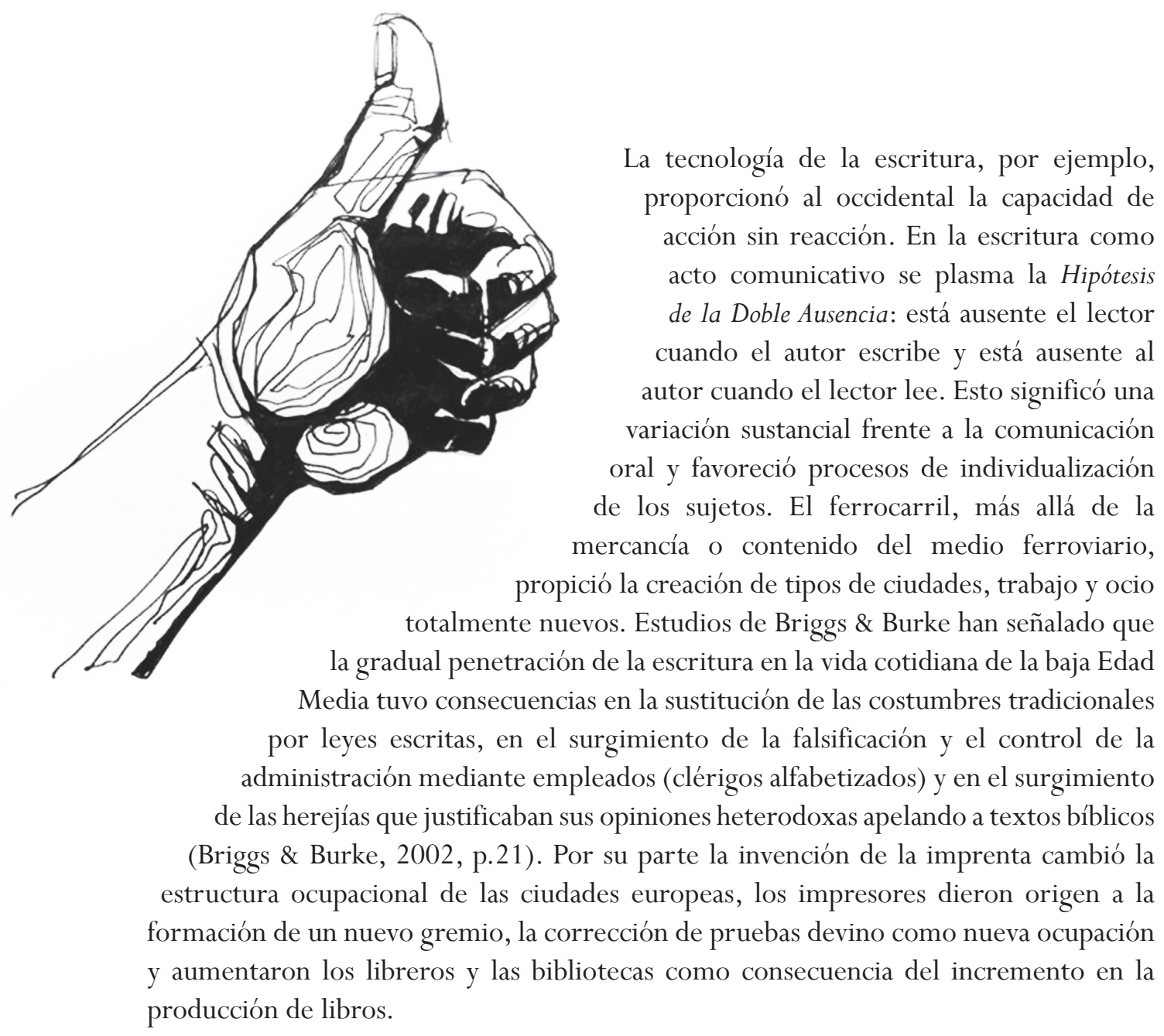

En medio de múltiples tecnologías que agencian prácticas humanas, Mc Luhan señaló que "Nos estamos acercando rápidamente a la fase final de las extensiones del hombre: la simulación tecnológica de la conciencia, por la cual los procesos creativos del conocimiento se extenderán, colectiva y corporativamente" (1996, p.25). En ese contexto anticipaba un tiempo en que la gente pasaría más tiempo en espacios cerrados y mediados por imágenes imperantes. Anticipaba la Era de la informática.

En una perspectiva más amplia es necesario señalar qué entendemos por medio de comunicación. El concepto histórico del periodismo, sus géneros y lenguajes deben abordarse desde una perspectiva cultural, ligada estrechamente a las transformaciones sociales, más allá que, exclusivamente, a los determinismos tecnológicos y los biografismos periodísticos. En perspectiva histórica se entiende que lo que se ha llamado medios de comunicación son sólo algunas formas precisas e instituidas, formalizadas, vinculadas con el poder, la información y el entretenimiento. Estudios como los de Asa Briggs y Peter Burke (2002) hacen compresible la tesis acerca de que toda materialidad sometida por acción del hombre a un proceso de significación, puede constituirse como potencial y efectivo medio de comunicación. Durante mucho tiempo los europeos del África subsahariana no se dieron cuenta que algunos pueblos africanos empleaban los tambores como un medio de comunicación a larga distancia, más rápido que el correo a pie o a lomo de caballo. La comunicación a larga distancia era una tecnología buscada por los europeos. 
En África, en 1730 Francis Moore observó hombres y mujeres que avanzaban por el río Níger y llevaban tambores de madera tallada a través de los cuales transmitían mensajes. Un siglo después William Alen observó que estos mensajes eran replicados de poblado en poblado y podían propagarse en un radio de ciento cincuenta kilómetros en cuestión de una hora. Transmitían frases hechas y aunque solo unos pocos podían comunicarse mediante los tambores, casi todo el mundo podía entenderlos (Gleick, 2012, p.23).

La historia material humana da cuenta una multiplicidad de medios y formas de la comunicación social. Briggs y Burke enumeran entre estas formas las estatuas e imágenes del mundo antiguo como medios de comunicación y propaganda política; las vías y el transporte, los caminos, las formas de comunicación física fluvial y terrestre que permitieron transmitir mensajes en coordenadas espaciales casi de forma inseparable hasta la invención del telégrafo; también las catedrales medievales y la arquitectura fueron medios de comunicación poderosos para configurar feligresías y producir efectos performativos en los creyentes religiosos, así como para enviar señales sobre las jerarquías del poder público. Lo que hoy conocemos como "los medios" son solo las formas dominantes de época, las hegemonías mediáticas. Sin embargo estos historiadores se preguntan ¿hay algo en el mundo que no sea comunicación? y recuerdan que LéviStrauss escribió sobre el intercambio de bienes y mujeres, mientras que Luhmann lo hizo sobre el poder, el dinero y el amor entendidos también como medios de comunicación. Han sido medios de comunicación en milenios anteriores el pergamino, la arcilla y la piedra, así como el papiro. En la Europa medieval, como la antigua Grecia, las cuales se han considerado culturas esencialmente orales "La predicación era un medio importante de difusión de información. Lo que ahora llamamos literatura medieval se producía... $<<$ no para un público lector, si no para un público oyente $>>$. La lectura se realizaba en voz alta" (2002, p.20). Los medios de comunicación, en su concepción actual, devienen como formas que subsumen la pluralidad de medios históricos de la comunicación; pero en la historia de la cultura no hay rupturas súbitas y si bien cada nuevo medio tiende a la monopolización del conocimiento, en la vida social coexisten, aunque con asimetrías, múltiples expresiones y entornos comunicativos.

\section{Los nuevos medios}

Manovich ha analizado las propiedades de la imagen en la era ciberespacial y los principios y características de los nuevos medios. Para él "las imágenes sintéticas creadas por ordenador no son una representación inferior de nuestra realidad, sino una representación realista de una realidad diferente" (2005, p. 26), de una realidad virtual.

Mc Luhan señaló que el contenido de un medio siempre es otro medio: el contenido de un libro es la escritura. El ordenador, nuevo medio, es en realidad un metamedio. 
En él las interfaces se comportan como "representaciones" de los viejos medios y sus formas culturales. Pero a diferencia de la imprenta y la fotografía "la revolución de los medios informáticos afecta a todas las fases de la comunicación y abarca la captación, la manipulación, el almacenamiento y la distribución; así como afecta también a los medios de otro tipo, ya sean textos, imágenes fijas y en movimiento, sonidos o construcciones espaciales" (2005, p.64). El computador es un sintetizador y manipulador de medios. En él los medios viejos se convierten en conjuntos de datos computables, se reconvierten en nuevos medios. Es esa perspectiva la que permite llamar nuevos a estos medios, su característica ontológica y no histórica, es la que le otorga dicha cualidad de novedad.

A diferencia del sentido común no es la interactividad una singularidad de los procesos mediados por el ordenador. Para Manovich,

“cuando empleamos el concepto de 'medios interactivos' exclusivamente en lo tocante a los medios que se basan en el ordenador, corremos el peligro de interpretar la interacción de manera literal, haciéndola equivaler a la interacción física que se da entre un usuario y un objeto mediático (pulsando un botón, escogiendo un enlace o moviendo el cuerpo), a expensas de la interacción psicológica. Pero los procesos psicológicos de completar lo que falta, de formación de hipótesis, de recuerdo y de identificación, que necesitamos para poder comprender cualquier tipo de texto o de imagen, son erróneamente identificados con una estructura de enlaces interactivos, de existencia objetiva". (2005, p. 105)

¿Dónde están entonces sus singularidades? Manovich ha distinguido cinco principios de los nuevos medios, tendencias principales mediante las cuales operan los objetos en el ordenador: la representación numérica, la modularidad, la automatización, la variabilidad y la transcodificación.

Representación numérica: Todos los objetos de los nuevos medios se componen de código digital, de representaciones numéricas; los medios pueden ser descritos por una función matemática, están sometidos a una manipulación algorítmica y en consecuencia pueden ser programables. Los objetos se convierten en unidades discretas. Una imagen reducida a su escala mínima puede distinguirse como una yuxtaposición de millones de pixeles. Todos los objetos: videos, mapas, fotos, textos, piezas sonoras, pinturas, etc., en su proceso de reconversión terminan digitalizados en un código binario compuesto por unos y ceros. Aunque en su representación tengan semejanzas con los viejos medios, están constituidos por una materialidad electrónica, radicalmente distinta.

Modularidad: Los nuevos medios se articulan mediante estructuras fractales. El objeto virtual presenta siempre la misma estructura modular (pixeles, polígonos, voxeles, caracteres o scripts). La World Wide Web es completamente modular, está articulada por páginas web compuestas de módulos. En ella la noción de fractal es metafórica. A diferentes escalas, las estructuras se acoplan formando macroconductas, significados de conjunto articulados por miles y millones de unidades discretas: pixeles que forman imágenes, páginas que forman portales, caracteres que forman frases, párrafos y palabras. 
Automatización: La codificación numérica y la modularización permiten la automatización: en el procesador hay herramientas, agentes que generan el esquema de un documento, el balance automático de blancos en una fotografía a través de Photoshop, el registro de un usuario y su sistema de verificación de identidad virtual, el acceso mediante digitación de hipervínculos; también existen rastreadores de tendencias para procesos automáticos de personalización en masa, y estos son algunos de los múltiples procesos en que se expresa la automatización digital.

Variabilidad o mutabilidad: En internet las páginas web mutan con facilidad, las plantillas o templates permiten cambiar sus formas de presentación de manera instantánea; las lógicas de producción a petición del usuario imperan mediante el rastreo de los gustos y selecciones de los cibernautas. Los portales y páginas responsives (sensibles) se adaptan a las formas y tamaños de los dispositivos, las pantallas y los navegadores. En internet se pueden crear distintas visualizaciones de contenidos a partir de los mismos datos. También la escalabilidad opera como principio de variabilidad.

En el entorno digital el ordenador subsume y reconvierte gran diversidad de medios. A su vez, en ellos el texto es un metalenguaje a través del cual se crean lenguajes de programación orientados a objetos e interfaces. Señala Manovich que una de las cualidades de los nuevos medios que carece de precedente histórico es la programabilidad. Éstos medios son programables y reestructurables, sus interfaces mutan, así como sus contenidos y formas expresivas para adaptarse cada vez más a las particularidades de cada navegante. Las tecnologías mediáticas reflejan los cambios sociales. En la sociedad industrial de masas se "suponía que todo el mundo debía disfrutar de los mismos bienes, se producían millones de copias idénticas. En cambio la sociedad postindustrial valora la individualidad por encima del conformismo. Cada ciudadano selecciona su ideología” (2005, p. 88).

Por su parte, a lo que Manovich llama objeto, Landow, desde una perspectiva discursiva llama Hipertexto. Este profesor de Lengua e Historia del Arte une los conceptos de la teoría literaria y la tecnología informática para comprender las características textuales del entorno virtual. Toma la definición que propone Nelson de Hipertexto: "me refiero a una escritura no secuencial, a un texto que se bifurca, que permite que el lector elija y que se lea mejor en una pantalla interactiva. De acuerdo con la noción popular, se trata de una serie de bloques de texto conectados entre sí por enlaces que forman diferentes itinerarios para el usuario" (s.r. citado por Landow, 2009, p. 25).

Conceptos como multilinealidad, nodos, enlaces y redes son claves para la comprensión de la arquitectura textual en el ecosistema informático. La estructura de un texto físico es vertical, está centrada alrededor de uno o varios puntos de vista, es jerarquizada y subordinada. El texto físico tiene elementos microestructurales que se cohesionan para formar una macroestructura arbórea. En contraste, en la red informática los textos son hipertextos, es decir, están ensamblados en una cadena mayor de textos; su estructura es horizontal, rizomática, raizal, descentrada, desjerarquizada. En un hipertexto una nota enlazada, una vez abierta aparece como un documento independiente, aunque asociado, 
y no como una especie de texto subsidiario, secundario u ocasionalmente parásito (Landow, 2009, p.28). Cada nodo o página está conectado a través de múltiples hipervínculos con textos de otras páginas o nodos y no hay un elemento macro que subordine a los demás. Un libro físico puede interpretarse como una plataforma textual o nodo con una red de referencias desconectadas físicamente del libro que el lector podría consultar por su propia cuenta. En la red informática los vínculos forman las redes textuales, los nodos están interconectados; los textos virtuales ofrecen múltiples entradas y desvíos, son hipertextuales.

Este proceso también transforma sensiblemente las características de la lectura y sus efectos de sentido, al punto que en internet se configura la noción de Texto de Lector, la cual otorga una autoría a éste último. En el libro físico accedemos a textos de autores: leemos escritos cerrados, acotados en sus contenidos y paginajes. La lectura es unidireccional, el contenido está claramente delimitado, tiene una unidad y una ruta de lectura específicas; es cohesionado y coherente, usualmente su publicación ha sido el resultado de un proceso previo de corrección de pruebas. Por su parte, en la red informática la estructura del texto es abierta y multidireccional, las páginas disponen un menú de vínculos opcionales al lector y éste fija la trayectoria; el texto es multidireccional, el repertorio lo decide quién lee (puede dar clicks sin pausa), el contenido no tiene límites. En internet cada artículo puede estar unido a numerosos trayectos y cada bloque de texto o imagen puede formar parte de varios "libros"; la ruta de lectura puede variar como en el juego de la rayuela. Internet ofrece mucho más contenido, en ella no hay un solo itinerario y podemos aventurarnos, pero también perdernos con mucha facilidad; podemos querer abarcarlo todo y en consecuencia correr el riesgo de no retener nada.

\section{Las mutaciones}

Tras la consolidación y emergencia de este sistema informático hoy asistimos a un proceso de mutación tecnocultural, a otra expresión de la sensibilidad humana, mutación de la tecnicidad, de la técnica convertida en sistema que configura nuevas sensibilidades. En su ensayo Mutación tecnocultural, convergencia entre tecnología y cultura, Martin-Barbero, atento al pulso de su tiempo, advierte que asistimos a un momento de mutación de las tecnicidades, al advenimiento de la técnica que deviene en sistema y trasciende su concepción instrumental. Tecnicidad que se constituye en uno de los factores que ha posibilitado una transformación de la sociedad y el conocimiento. Frente a las resistencias de algunos sectores por las mutaciones digitales y la apología tecnológica casi fetichista por parte de otros, sostiene Martin-Barbero que tenemos una pésima combinación de determinismo tecnológico y pesimismo cultural. En medio de tal dicotomía la mediación tecnológica de la comunicación deja de ser meramente instrumental para convertirse en estructural. En ella emergen nuevas sensibilidades, nuevos hábitos de lectura, nuevas subjetividades, La tecnología, que durante siglos fue tenida por un mero instrumento, ha pasado a convertirse en razón y por ello es clave pensar la relación entre técnica y cultura; tenemos "un nuevo sistema técnico a escala planetaria que transforma el uso del tiempo al producir la convergencia y simultaneidad de los momentos en todo el mundo" (2012, s. p.). 


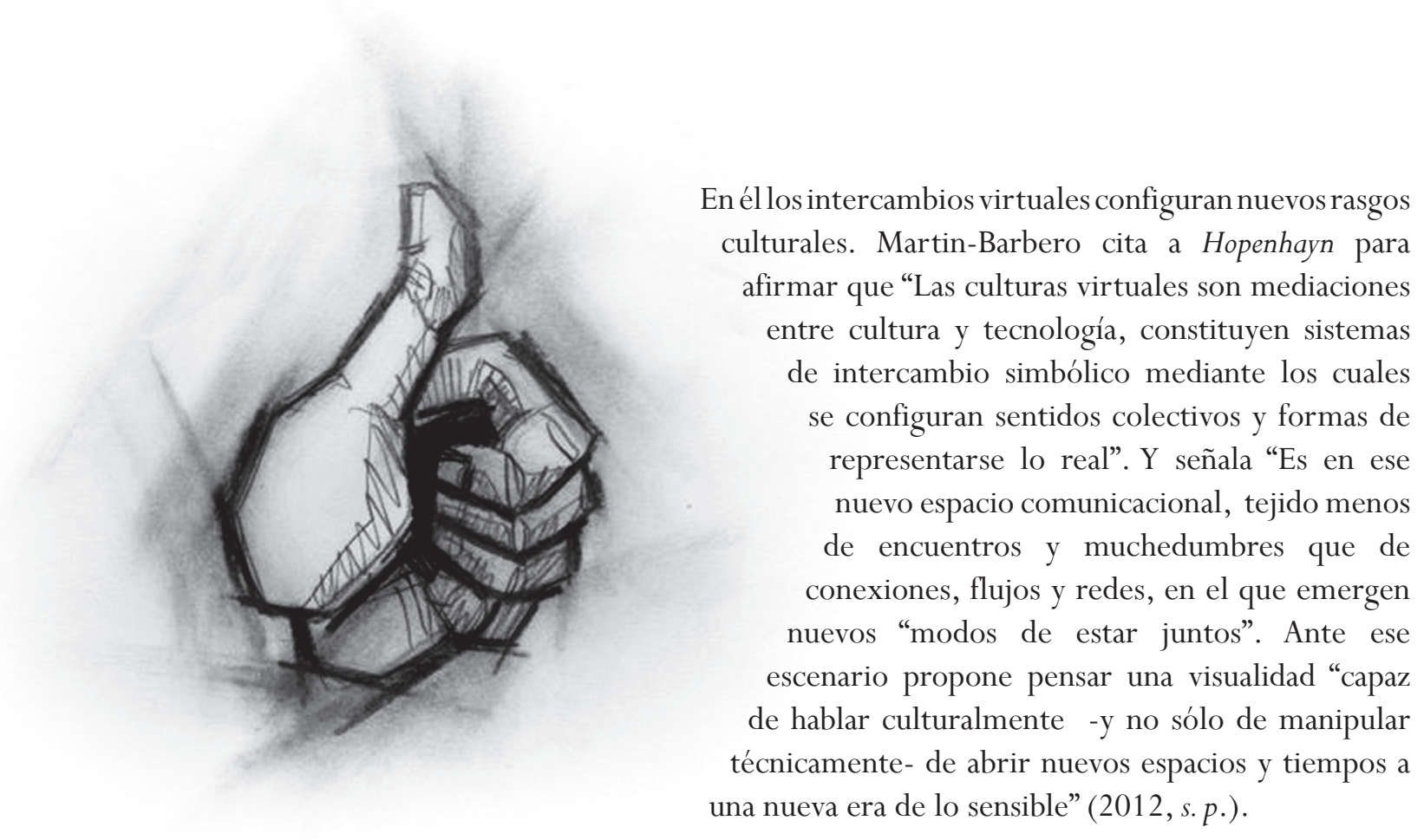

Esta transformación ha generado una reflexión y reconceptualización de las tecnologías, así como un interés por historizar los procesos de transformación social que ella ha mediado. También ha desnaturalizado la interpretación del libro como objeto cultural y ha despertado un interés por entender la escritura en la perspectiva de tecnología cognitiva.

En medio de un remesón de una magnitud que algunos investigadores solo comparan con el producido por la invención de la escritura y la creación de la imprenta, sensibles transformaciones se han generado en todos los Campos de la experiencia social, incluidos por supuesto las artes y las humanidades.

Se han producido crisis de los campos de la producción social, entre ellos los campos periodístico, editorial y musical. Para nuestro interés revisemos el campo periodístico. En él dicha crisis se expresa a su vez en crisis de los géneros de categorización; las teorías de los géneros periodísticos han quedado obsoletas frente a la emergencia de nuevas nociones de la noticiabilidad, la creciente inserción de una estética posmoderna y la consolidación de géneros propios del espacio virtual como la videoinfografía.

Se han disuelto los límites que trazaban las fronteras disciplinares; gracias a la convergencia de los objetos de estudio, oficios y disciplinas como el periodismo, el diseño gráfico y el arte digital convergen desde diversas perspectivas en los estudios sobre el Big Data, los hipertextos informáticos y las narrativas transmedia.

Se han presentado crisis de los roles relativamente estables ligados con la comunicación de masas, roles como el de productor, lector, medio periodístico, así como transformaciones en las estructuras internas de los propios medios. Se han presentado crisis de los conceptos explicativos que durante décadas sirvieron para definir e interpretar el campo. La noción de periódico que aludía a una estable periodicidad en la divulgación de contenidos queda obsoleta frente a las posibilidades de los nuevos medios en Internet, así como la noción de consumidor de información y medio de comunicación. 
Durante varios años, en medio del remesón, se definió por asociación como crisis del periodismo lo que en realidad ha sido una crisis del modelo de negocios del periodismo industrial. Las agencias publicitarias trasladaron sus inversiones en compañías de difusión multiplataformas como Google y otras del entorno digital. Por su parte, las mutaciones en la sensibilidad y en las subjetividades han generado transformaciones en los modos de lectura y una emergencia de nuevos criterios para la producción y visibilización de contenidos (like e internet). Han emergido nuevas necesidades y demandas, nuevos actores y agentes agregadores de contenidos. La creación de Wikileaks ${ }^{3}$, definida como una agencia de inteligencia de la gente, y el nacimiento de salas de redacción independientes que se sustraen a las agendas de las juntas directivas corporativistas hacen parte del nuevo escenario.

Han emergido diversas formas de trabajo liberado cooperativo y se han desarrollado grandes obras creativas de código abierto como gestores de contenido, repositorios de trabajo y enciclopedias tipo wiki. Se ha generado, no exento de conflictos y restricciones, una mayor democratización y acceso a representaciones digitales de grandes obras de la humanidad. Han surgido técnicas personalizadas de investigación y conceptos para el ecosistema informático como Minería de datos; otros conceptos prevalecientes en décadas anteriores como comunicación de masas dan paso a procesos de personalización en masa. A la par con este proceso han emergido nuevos centros de recursos, redes sociales y sistemas de indexación y producción de contenidos. Se ha redefinido el concepto de historia periodística ${ }^{4}$ hacia una concepción posmoderna. Esto en medio de un desarrollo permanente de plataformas y recursos para múltiples instancias de la comunicación generando con ello mayores posibilidades para la investigación.

En una perspectiva vinculada con las transformaciones de las prácticas culturales y desligada del determinismo tecnológico y el biografismo periodístico, puede interpretarse un concepto histórico de la prensa en tensión frente a las formas heredades de la comunicación pública y los llamados periodismos modernos: el periodismo ideológico, el periodismo informativo y una tercera categoría entendida como periodismo complejo. Este último tipo de periodismo supone una superación desde expresiones internas y externas de las agotadas fórmulas del periodismo informativo industrial. Para Julián González "lo esencial del periodismo complejo es... la desrealización de lo real, lo que devalúa el núcleo duro del canon informativo clásico, al poner en crisis la confianza en los $<<$ hechos $>>$ y en las operaciones de constatación (neutralidad informativa, objetividad periodística)" (2004, p.36). Como parte de ese proceso de des-realización de lo real pueden enmarcarse el Periodismo postfactual, el ciberperiodismo y el Periodismo Asistido por Computador: conceptos derivados de una tendencia que incorpora nuevos criterios para comprender la comunicación de información. Ligados a estas prácticas surgen conceptos como Crowdsourcing y Narrativa Transmedia. Este último a su vez como superación de conceptos antecesores como hipermedia y crossmedia. 


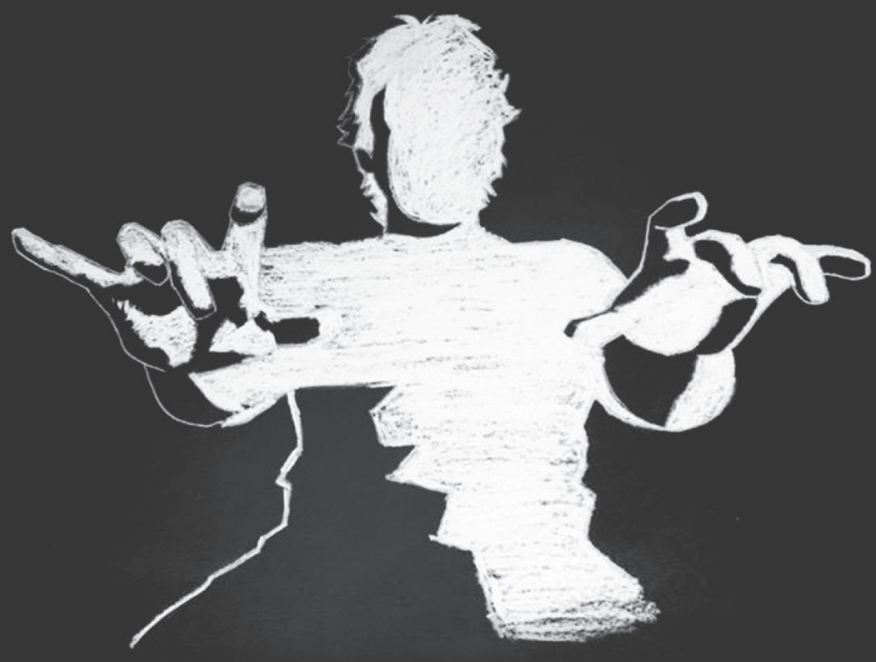

El entorno informático es el entorno de la superabundancia y en él se han consolidado prácticas como la curaduría automática y manual de contenidos digitales, las técnicas y estrategias de posicionamiento en motores de búsqueda e indexación, los sistemas SEO, así como nuevas tecnicidades y literacidades. Una emergencia de oficios, conceptos y prácticas derivadas de un progresivo proceso de reconversión de los objetos materiales a signos móviles. Esta es una de las principales características del fenómeno cibernético: objetos de los más diversos usos, tamaños y contextos son reconvertidos en los ordenadores. La biblioteca, el escritorio, la página, el museo, la enciclopedia, el libro, la ventana, el cd, la sala y la oficina ahora hacen parte de los nuevos medios.

Cuando nos conectamos entramos a un entorno alegórico, dispuesto por metáforas que vinculan la experiencia informática con la historia cultural. La lectura de un texto en una página web asemeja el retorno a la lectura en el papiro egipcio. El scroll nos permite simular el desenrollamiento de un texto ininterrumpido (Manovich, 2005, p.126). Cuando usamos el software Photoshop nos desenvolvemos en un entorno que alegoriza las herramientas y prácticas de un laboratorio de fotografía: íconos como pincel, filtro, recortar, sobreexponer, saturar, aumentar o disminuir opacidad recrean las actividades que desarrollaban de forma artesanal los fotógrafos en sus laboratorios de imagen.

Como un medio de medios el ordenador y la red informática demandan toda nuestra atención en sus contenidos; sin embargo, es necesario recordar el llamado de Mc Luhan a atender su mensaje, a analizar el cambio en los patrones, frecuencias o escalas que genera en las conductas humanas. Los investigadores citados en esta investigación coinciden en señalar desde diversas formas y puntos de vista la necesidad de trascender una interpretación meramente instrumental de estas tecnologías. Para Manovich los medios pueden parecer medios pero esa es solo su superficie. Señala que

"la informatización de la cultura lleva a cabo de manera gradual una transcodificación similar en relación con todas las categorías y conceptos culturales, que son sustituidos, en el plano del lenguaje o del significado, por otros nuevos que proceden de la ontología, epistemología, y la pragmática del ordenador. Por tanto, los nuevos medios actúan como precursores de este proceso de carácter más general de reconceptualización cultural". (Manovich, 2005, p.94) 
Nicholas Carr se ha interesado por comprender las mutaciones y transiciones generadas por la tecnología informática con respecto a los modos en que leemos. Señala que si bien una página de texto vista en una pantalla parece igual a una página del texto impreso, el hecho de desplazarse o hacer click implica una postura corporal distinta y que dicha postura a su vez está implicada en el acto de conocer; hay una experiencia sensoriomotriz de la materialidad que es modificada con los nuevos medios (2011, p.114).

Toda tecnología es una expresión de la voluntad humana y Carr indica que nuestras tecnologías se pueden dividir, a grandes rasgos, en cuatro categorías, según su forma de complementar o ampliar nuestras capacidades innatas: 1. Tecnologías para aumentar nuestra fuerza y resistencia físicas: como el arado, la aguja de zurcir y los escudos de combate; 2. Tecnologías para extender el alcance o la sensibilidad de nuestros sentidos: como el microscopio, el micrófono y el teléfono; 3. Tecnologías para remodelar la naturaleza al servicio de nuestras necesidades: como la píldora anticonceptiva y las represas; y 4. Tecnologías intelectuales para ampliar o apoyar nuestra capacidad mental: como la máquina de escribir, el libro, el ábaco y el computador.

Carr coincide con Mc Luhan y recuerda que cuando creamos un producto éste genera subproductos que solemos desestimar y éstos muchas veces pueden ser más significativos e impactantes que el producto mismo. Cada tecnología comporta una ética intelectual que muchas veces trasciende, incluso, la intención del propio creador y del consumidor. Pero, podemos ver con mayor facilidad los subproductos derivados de las tres primeras tecnologías y nos cuesta mayor dificultad identificar los subproductos de la cuarta tecnología, de aquellas diseñadas para extender las capacidades intelectuales.

Cuando la gente encuentra que cualquier ganancia particular de una nueva tecnología de la información compensa las pérdidas, está afirmando que representa el progreso; cuando sufre más pérdidas que ganancias, experimenta la nueva tecnología informacional como una decadencia cultural (Landow, 2009, p.56). En el mismo sentido se expresó Ong cuando estudió las relaciones entre la oralidad y la escritura; señaló que las tecnologías no son meras ayudas exteriores, sino también transformaciones interiores de la conciencia, especialmente cuando afectan a la palabra. La historia de la lengua es también una historia de la mente.

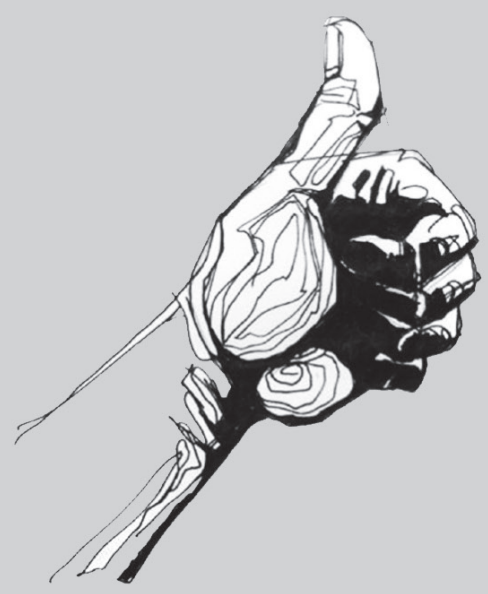




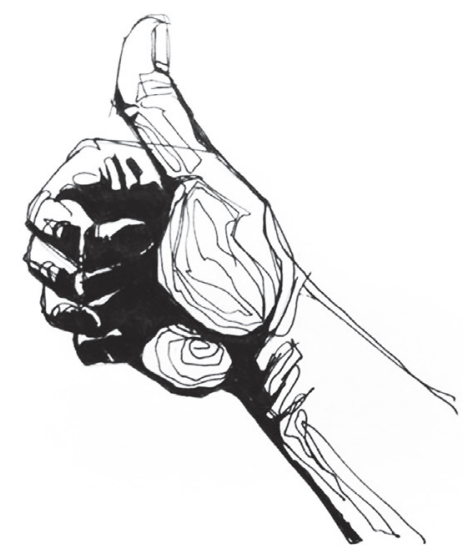

Toda tecnología intelectual encarna una ética intelectual, un conjunto de supuestos acerca de cómo funciona o debería funcionar la mente humana: "Lo que hizo el mapa con el espacio, traducir un fenómeno natural a una concepción artificial e intelectual de dicho fenómeno, lo hizo otra tecnología, el reloj mecánico, con el tiempo" (Carr, 2011, p. 58). Los usuarios se centran en los beneficios prácticos que obtienen al emplear la herramienta, se centran en sus contenidos y, en consecuencia, también son ajenos a su ética. Pero, en última instancia, es la ética intelectual de la invención la que surte el efecto más profundo: "La interactividad de la red nos dota de nuevas y potentes herramientas con que recabar información, expresarnos y conversar con otras personas. También nos convertimos en cobayas de laboratorio que accionan constantemente palancas a cambio de migajas de reconocimiento social o intelectual" (Carr, 2011, p. 146). Los procesos de reconversión digital, el surgimiento de medios que metaforizan gráficamente los viejos medios incorporan cambios significativos en las prácticas humanas.

Estos son primeros esbozos de un programa de indagación tendientes a favorece la comprensión y usos de la tecnología por parte de la ciudadanía. La tecnología del ordenador e internet devino como promesa pero también como amenaza. No obstante, entre el pesimismo cultural y fetichismo tecnológico, es necesario abrir otros horizontes para comprender la nueva geografía humana, los puntos de su constelación.

\section{Notas}

${ }^{1}$ Este texto se deriva del proyecto de investigación "El mensaje de los nuevos medios:Análisis de transformaciones en prácticas culturales locales propiciadas por la emergencia de internet", realizado en el marco del Grupo de Periodismo e Información de la Escuela de Comunicación Social de la Universidad del Valle. Esta investigación es pensada como primera exploración de un conjunto de investigaciones que permitan dirimir patrones de reconfiguración tendientes al diseño de productos que favorezcan los usos de los nuevos medios de la comunicación social.

${ }^{2}$ Este texto se deriva del proyecto de investigación "El mensaje de los nuevos medios:Análisis de transformaciones en prácticas culturales locales propiciadas por la emergencia de internet”, realizado en el marco del Grupo de Periodismo e Información de la Escuela de Comunicación Social de la Universidad del Valle. Esta investigación es pensada como primera exploración de un conjunto de investigaciones que permitan dirimir patrones de reconfiguración tendientes al diseño de productos que favorezcan los usos de los nuevos medios de la comunicación social. 
${ }^{3}$ En una entrevista realizada por Semana a su fundador Julian Assange se le interroga por la naturaleza de Wikileaks: SEMANA: “¿Clasificaría a WikiLeaks como un alborotador del establecimiento, como un activista del derecho a estar informado, como una superfuente de información en la nueva era digital o como una forma de hacer periodismo? J.A.: Es todo eso. Estamos planteando nuevos estándares. ¿Para qué es el periodismo? No es solo para que los dueños de los medios tengan ganancias, debe buscar un servicio público. No es solo para producir ganancias... WikiLeaks no es una organización convencional. Trabajamos por el derecho que tiene la gente a saber y a publicar”. http:/ / www.semana.com/nacion/colombia-muy-interesante-para-wikileaks/153606-3.aspx

${ }^{4}$ En el artículo que referencio en la bibliografía final cuento como en un ensayo publicado en la revista Harvard acerca de las nuevas voces del periodismo en América, Juanita León expone ocho características de la transformación que viene presentando el periodismo en las nuevas tecnologías. Para ella, ahora también es noticia la información cruda, antes considerada insumo y no publicada por las restricciones de espacio de los medios tradicionales, restricciones superadas en internet. También es historia en sí misma el contexto en que se producen los hechos, es historia el proceso de hacer la historia, así como la construcción colectiva de la noticia con los usuarios y el cubrimiento en tiempo real; es historia la noticia como experiencia de inmersión virtual mediante técnicas de simulación de situaciones y son historia las propias herramientas con que se crean en la red; así como la conversación agregada y comentada por los usuarios constituyen la historia periodística.

\section{Referencias}

Baricco, A. (2008). Los bárbaros. Ensayos sobre la mutación. Bacelona: Anagrama.

Briggs, A. \& Burke, P., (2002). De Gutenberg a internet: Una historia social de los medios de comunicación. Madrid: Taurus.

Capra, F. (1998). La trama de la vida: Una nueva perspectiva de los sistemas vivos. Barcelona: Anagrama.

Carr, N. (2011). Superficiales: ¿qué está haciendo internet con nuestras mentes? México, D.F: Taurus.

Cassany, D. (2012). En_línea: Leer y escribir en la red. Barcelona: Editorial Anagrama.

Certeau, M., Giard, L., \& Pescador, A. (2007). La invención de lo cotidiano. México: Universidad Iberoamericana.

Deleuze, G. \& Guattari, F. (1977). Rizoma. Parma-Lucca: Pratiche editrice.

Galindo, C. (1998). Técnicas de investigación en sociedad, cultura y comunicación. Argentina: Addison Wesley Longman.

García, K. (2011). Wikileaks y las expresiones del periodismo transformado. En Revista Nexus 9, 244-259.

Gleick, J. (2012). La información: Historia y realidad. Barcelona: Crítica.

González, J. (2004). Repensar el periodismo:Transformaciones y emergencias del periodismo actual. Cali: Programa Editorial, Universidad del Valle.

Johnson, S. (2003). Sistemas emergentes: O qué tienen en común hormigas, neuronas, ciudades y software. Madrid: Turner.

Kozak, C., \& Castromán, E. (2012). Tecnopoéticas argentinas:Archivo blando de arte y tecnología. Buenos Aires: Caja Negra.

Landow, G. P. (2009). Hipertexto 3.0: La teoría crítica y los nuevos medios en una época de globalización. Barcelona: Paidós.

León, J. (Spring-summer 2011). La Silla Vacía. Eight Ways the Internet Changes the Way We Think about the News. En ReVista. Harvard Review of Latin America. Recuperado en mayo 20 de http: / / www.drclas.harvard.edu/publications/revistaonline/spring-summer-2011/ la-silla-vacía

Levy, Pierre. (1999). Cibercultura. São Paulo: Editora 34.

Manovich, L. (2005). El lenguaje de los nuevos medios de comunicación: La imagen en la era digital. Barcelona: Paidós. 


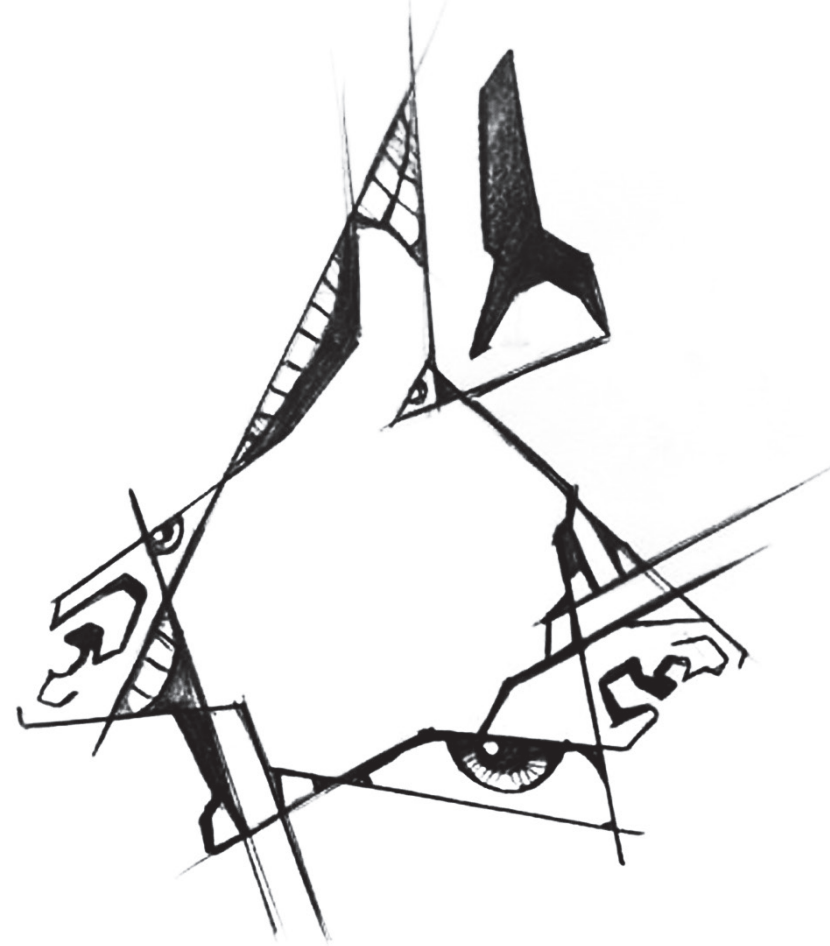

Manovich, L. (2013). El software toma el mando. Barcelona: Editorial UOC.

Martín, S. M. (2007). Teoría de la comunicación: La comunicación, la vida y la sociedad. Madrid: McGraw Hill. Martín-Barbero, J. (2012). Mutación tecnocultural, convergencia entre tecnología y cultura. Material de trabajo en el Seminario La Comunicación Universidad / Sociedad en la mutación de las tecnicidades, del conocimiento y del arte. Cali: Universidad del Valle.

Martín-Barbero, J. (1987). De los medios a las mediaciones: Comunicación, cultura y hegemonía. México: Ediciones G. Gili.

Mattelart, A. (2002). Historia de la sociedad de la información. Barcelona: Paidós.

McLuhan, M. (1996). Comprender los medios de comunicación: Las extensiones del ser humano. Barcelona: Paidós.

Moragas, S. M. (2011). Interpretar la comunicacion: Estudios sobre medios en América y Europa. Barcelona: Gedisa.

Morin, E. (1994). Introducción al pensamiento complejo. Barcelona: Gedisa.

Scolari, C. (2008). Hipermediaciones. Elementos para una Teoría de la Comunicación Digital Interactiva. Barcelona: Gedisa.

Scolari, C. A. (2013). Narrativas Transmedia: Cuando todos los medios cuentan. Barcelona: Centro Libros PAPF, S.L.U. 